\section{FUNCTION OF THE CORPUS CALLOSUM IN SCHIZOPHRENIA}

DEAR SIR,

We read with interest the paper by Shagass et al, (Journal, May, 1983, 142, 471-76) and their failure to replicate the work of Jones and Millar (Journal, 1981, $139,553-57$ ) in relation to possible dysfunction of the corpus callosum in schizophrenia.

Jones and Miller reported finding a relative synchrony of contralateral and ipsilateral somatosensory evoked potentials (SEP's) in a schizophrenic group as compared with a definite latency in normal controls. Shagass, using a similar technique of vibrotactile stimulus to the index finger, found that few of his subjects had distinct ipsilateral responses. From his monopolar recordings he felt that possibly the vertex reference electrode used by Jones and Millar contributed to a spurious ipsilateral responses because it was not an inactive reference. This had been pointed out earlier by Desmedt and Brunko (1980) commenting on Salamy's (1978) technique of measuring interhemispheric conduction time. Shagass felt that this was consistent with evidence that distal parts of the limbs do not have callosal connections.

We have recently completed a study (to be published) on SEP's in eight control and six epileptic subjects with chronic psychosis. We used the more traditional technique of left and right median nerve stimulation with the vertex as common reference electrode. We found like Shagass that the ampitudes of the ipsilateral responses were smaller than the contralateral responses to such an extent that is was often difficult to make reliable ipsilateral latency measurements. Where such measurements could be made we found no significant differences between the latencies for ipsilateral or contralateral evoked responses in either the normal or patient groups. Results for the $P 1$ and $P 2$ peaks are shown in the Table. (Results quoted are for left and right median nerve stimulation averaged).

\begin{tabular}{lccc}
\multicolumn{4}{c}{ TABLE } \\
\hline Controls n=8 & $21 \pm 4$ m.sec. & $46 \pm 6 \mathrm{~m} . \mathrm{sec}$. & Contra \\
& $23 \pm 4 \mathrm{~m} . \mathrm{sec}$. & $47 \pm 5 \mathrm{~m} . \mathrm{sec}$. & Ipsi \\
& n.s. & n.s. & \\
\hline Epileptics & $27 \pm 5 \mathrm{~m} . \mathrm{sec}$. & $52 \pm 8 \mathrm{~m} . \mathrm{sec}$. & Contra \\
with n=6 & $31 \pm 6 \mathrm{~m} . \mathrm{sec}$. & $56 \pm 8 \mathrm{~m} . \mathrm{sec}$. & Ipsi \\
Psychosis & n.s. & n.s. & \\
\hline
\end{tabular}

Latencies were significantly greater for the patient group but this could be accounted for by the age difference between the groups (controls $29 \pm 5$ years, Epileptics $41 \pm 13$ years).

Gulmann et al (1982) recently reported a study of ipsilateral and contralateral SEP's in ten controls and ten chronic schizophrenic patients using median nerve stimulation. They found, using bipolar recording, an ipsilateral response only corresponding to peak 5 of the contralateral SEP, i.e. at latency greater than 65 $\mathrm{m} . \mathrm{sec}$. This is somewhat longer than the peaks we looked at.

Our study left us like Shagass $e t$ al feeling that the use of SEP in comparing ipsilateral and contralateral responses as a technique for measuring callosal function needs further careful study before it is likely to be able to help us answer the question about possible corpus callosal dysfunction in schizophrenia.

\section{P. FENWICK \\ D. BRENNAN \\ M. PHILPOT}

Maudsley Hospital,

Denmark Hill,

London SE5 8AZ

\section{References}

Desmedt, J. E. \& Brunko, (1980) Functional organisation of far-field and cortical components of somatosensory evoked potentials in normal adults. In Clinical Uses of Cerebral Brainstem and Spinal Somatosensory Evoked Potentials. (ed. J. E. Desmedt). Basel: Karger.

Gulmann, N. C., Wildschiødtz, G. \& ØrBaEK, K. (1982) Alteration of interhemispheric conduction through corpus callosum in chronic schizophrenia. Biological Psychiatry, 17, 585-93.

Jones, G. H. \& Miller, J. J. (1981) Functional tests of the corpus callosum in schizophrenia. British Journal of Psychiatry, 139, 553-7.

SAlamy, A. (1978) Commisural transmission: maturational changes in humans. Science, 200, 1409-11.

Shagass, C., Josiassen, R. C., Roemer, R. A., Straumanis, J. J. \& Slepner, S. M. (1983) Failure to replicate evoked potential observations suggesting corpus callosum dysfunction in schizophrenia. British Journal of Psychiatry, 142, 471-6.

\section{Dear Sir,}

\section{MUNCHAUSEN SYNDROME}

Munchausen Syndrome presenting a psycho-social symptomatology is now a well-described condition (Cheng and Hummel, 1978; Simpson, 1978; Snowdon et al, 1978). However it is infrequently referred to in text-books, and trainees often remain ignorant of its existence.

The most typical case would appear to be a single male, usually referred from the medical or surgical wards, often following an overdose or other suicide attempt. The mood is usually depressed and this is often associated with a feigned and dramatic bereavement such as multiple deaths of relatives in a car crash, often in a different country. The history, for one reason or another, cannot be corroborated. 